\title{
The Applications of Biodegradable Polymers on Soil and Water Conservation Engineering
}

\author{
Chunku Lu ${ }^{a}$, Lianghsing $\mathrm{Chou}^{\mathrm{b}}$ \\ Department of Civil and Water Resources Engineering, National Chia-Yi University, Taiwan \\ a zivlu@msn.com, ${ }^{b}$ Ihchou@mail.ncyu.edu.tw
}

\begin{abstract}
Key words: Hydroseeding, PAM, Aggregates stability, Seeds germination.
Abstract. Polyacrylamide (PAM), a biodegradable polymer, has been used in irrigating ditch to reduce soil loss for a long time. It can also be used as an aggregate agent to keep the balance of soil and water. The performance of PAM as a soil aggregate agent of silty clay loams was conducted by the wet-sieving method in this study. The effects of PAM on the germinations and growths of Bermuda and Bahia were observed by irrigating seeds of the grasses with various concentrations of PAM solutions. The experiments were conducted in a controlled box with constant temperature and humility. An out-door experiments was also tested to understand the germination rate of seeds and the development of roots of grasses in ambient condition.
\end{abstract}

\section{Introduction}

Hydroseeding (or hydraulic mulch seeding, hydro-mulching, hydraseeding) is a planting process which utilizes slurries of seed and mulch. It promotes quick germination and inhibits soil erosion. The mulch in the hydroseed mixture helps maintain the moisture level of the seed and seedlings. The slurry often has other ingredients including soil conditioners and other additives. The ingredients should have great effects on the adhesion of the hydrocolloids and the germination of seeds. Polyacryamide (PAM) and polyvinyalcohol (PVA) are two water-soluble and biodegradable polymers which commonly used as soils conditioner in agriculture. In this work the effects of PAM on the aggregation of soils, the germination of herbaceous seeds, and the development of roots of herbaceous plants were studied.

There are many studies concerning utilizations of PAM in agriculture. Levy and Miller (1999) observed the adsorption of anionic PAM on soils [1]. They concluded that the PAM adsorption may not restricted to outer aggregate surfaces only. Lu et al (2002) studied the effect of soil and water properties on anionic polyacrylamide sorption [2]. Barvenik (1994) reviewed the characteristics of polyacrylamide related to soil application [3]. Miller et al (1998) studied the aggregate stabilization in kaolinitic soils and envisaged the use of PAM could be a viable alternative to the commonly used solid and water conservation practices [4].

\section{Experiments}

\subsection{Materials}

(1) Soil: The soils used in this study were gotten from the eastern of Chiayi city, Taiwan. They belong to silty clay loam according to the classification of agricultural use.

(2) PAM: $15 \%$ HPAM was used. The molecular weight of PAM was 5-6 mg/mole with monomer (AMD) contents less than $0.05 \%$ to fulfill the requirement of agriculture use.

Grass seeds: Two herbaceous species of seeds commonly utilized for water and soil conservation were used in the experiments. They were Bermuda and Bahia.

\subsection{Procedures:}

(1) Aggregates stability:

Wet-sieving method as used by Levy and Miller (1999) was applied to understand the stability of soil aggregates. For each size class of soils the stability of aggregates was evaluated by the mean weight diameter (MWD), which was calculated using the following equation 
$\mathrm{MWD}=\sum_{i=1}^{n+1} \frac{r_{i-1}+r_{i}}{2} \times m_{i}$

The concentrations of PAM used in this experiment were 100 ppm, 200 ppm, 300 ppm, 400 ppm. A controlled sample with 0 ppm PAM was conducted for comparison.

(2) Germination experiments

The seeds for the germination experiment were chosen according to ISTA standard method. The germination of grass seeds was conducted in a box with the temperature controlled between 20-25 ${ }^{\circ} \mathrm{C}$. Seeds were placed on plates soaked with solutions of various concentrations of PAM. The controlled samples were placed on plates soaked with deionized water. The germination number of seeds were observed and recorded every day.

(3) Outer-door experiments.

To understand the effect of ambient condition on the germination of seeds and the development of grasses, an outer-door experiment was conducted. The soils used in this experiment were silty clay loam as described previously. Soils were put in box with dimension 340*260*75 mm. There were 15 holes with diameter $4 \mathrm{~mm}$ in the bottom of the box for drainage. Bermuda and Bahia were used in this study because they were commonly applied in soils and water conservation engineering. The grasses were cultivated with PAM solutions with various concentrations ( $0 \mathrm{ppm}, 10 \mathrm{ppm}$, $100 \mathrm{ppm}$ and 1000ppm). The roots of the grasses were observed and recorded 30 days after seeding.

\section{Results and discussion}

3.1 Aggregate stability. Figure 1 shows the microscopic surfaces of soils treated with PAM. It is clear that PAM dispersed on the surfaces of soils. The binding forces between PAM and soils can increase the dimensions of aggregates and stabilize the aggregates. Figure 2 shows the experimental results of wet sieving. With the increase of PAM used, the loss of soils decreased. For the controlled sample, the loss of soils was 51.9\%. Soils treated with 400 ppm PAM, the loss reduced to 33.34\%. It was worth noting that most of the reductions of soils were small particles. We can conclude that PAM can enhance the aggregates of soils and prevent soils from erosion. The effects of the enhancement are more significant for small particles of soils than the large particles.

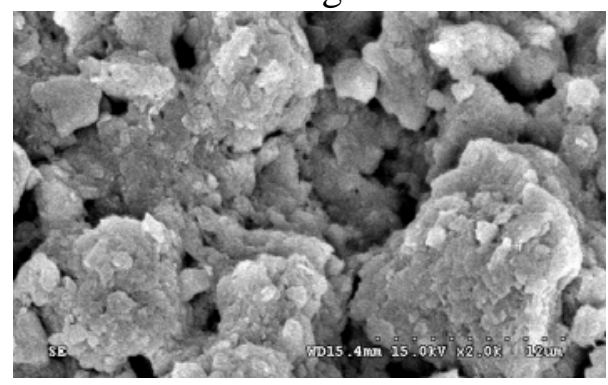

Fig. 1. PAM on soil surface

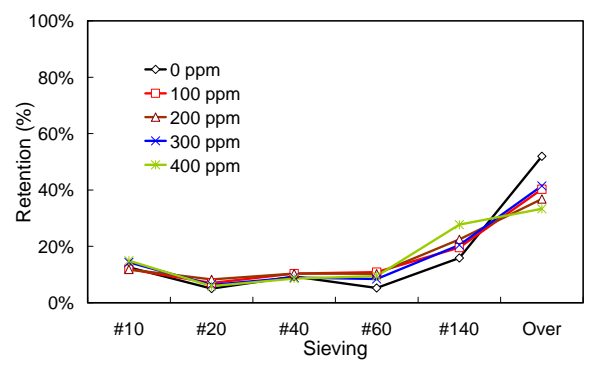

Fig. 2. Comparison of wet-sieving of soils treated with PAM

3.2 Germination of seeds development of grasses. The germinations of Bermuda seeds are shown in figures 3 and figure 4. There are four various concentrations of PAM solutions in this experiment. In addition to the controlled sample ( deionized water), $0.5 \mathrm{ppm}, 1 \mathrm{ppm}$, and $2 \mathrm{ppm}$ solutions of PAM were used. The development of grasses was shown in figure 3 and the germination trend was shown in figure 4. It is clear that no significant difference of the rate of germination was observed in figure 4. However germination of seeds in PAM solution was delayed for a few days compared with that of the controlled samples. This germination trend could be contributed to the adsorption PAM onto the surface of seeds and reduced the transport of water into seeds in early time. Figure 3 depicted that the development of grasses was significantly affected by the existence of PAM as depicted. Grasses in high concentration of PAM grew faster than grasses in low concentration of PAM. The experimental results of Bahia had the similar results. The experimental results gave the evidence that PAM could enhance the developments of Bermuda and 
Bahia and had no significant effects on the germinations of their seeds. It is therefore believed that the amide function group of PAM can be used as fertilizer of nitrogen resource.

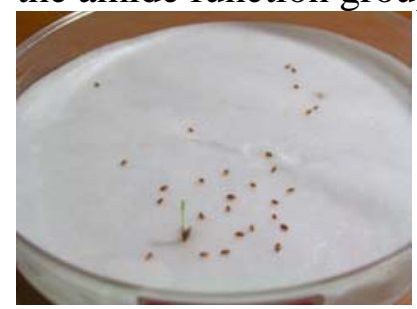

a. deionized water

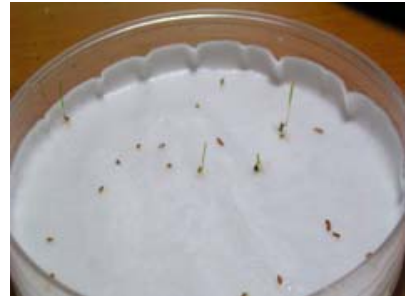

b. 0.5 ppm PAM

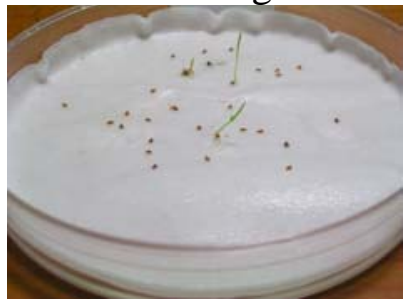

c. 1 ppm PAM

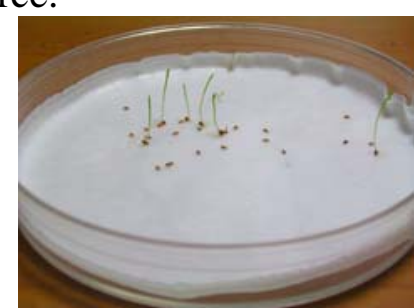

d. 5 ppm PAM

Fig. 3. Comparison of Bermuda grass development with various PAM concentration (7 days);a. de-ionized water, b. 0.5ppm, c.1ppm, d. 5ppm

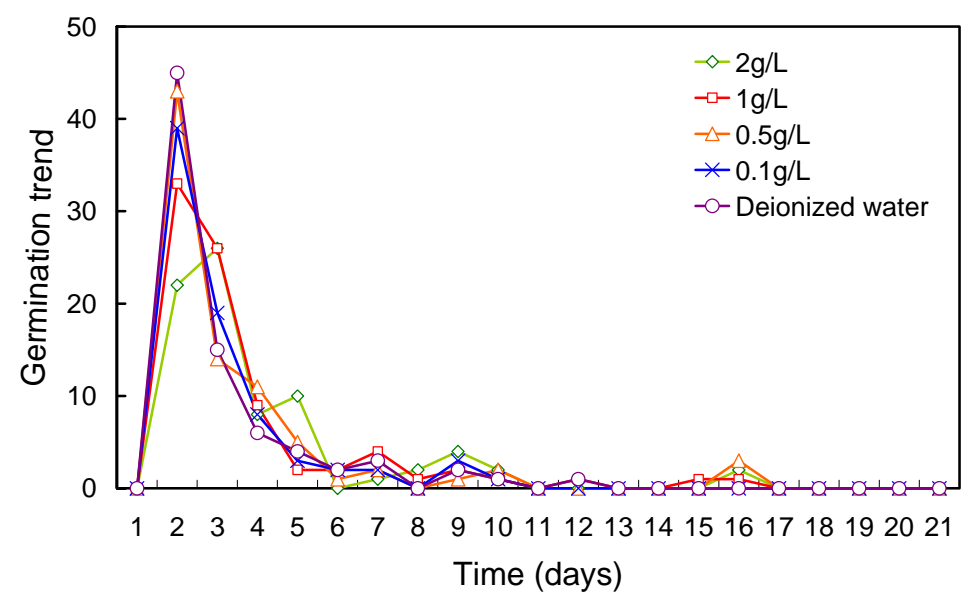

Fig. 4. Germination trend of Bermuda grass $\left(\mathrm{T}=25-30^{\circ} \mathrm{C}\right)$

3.3 Development of roots of plants. The out-door experiment was used to observed the development of roots of grasses. Table 1 and table 2 give the germinations and length of roots of Bermuda and Bahia. The effects of concentration of PAM on length of roots were depicted in figure 5 and figure 6. It is clear that roots of both the grasses grew faster than that of the controlled sample ( $0 \mathrm{ppm})$. The results were coincident with the growth of grasses in the experiment described in previous section. However the concentration of PAM has significant effect on the germination of Bermuda. It is suggested the application rate of PAM should not exceed $1000 \mathrm{ppm}$.

Table 1 Germination percentage and root length of the Bermuda grass in field test.

\begin{tabular}{lcccccc}
\hline \multicolumn{2}{l}{ Conc. Of PAM } & $10000 \mathrm{ppm}$ & $1000 \mathrm{ppm}$ & $100 \mathrm{ppm}$ & $10 \mathrm{ppm}$ & $0 \mathrm{ppm}$ \\
\hline \multicolumn{2}{l}{ Germination percentage } & $43 \%$ & $55 \%$ & $49 \%$ & $55 \%$ & $43 \%$ \\
\multirow{2}{*}{ Root length } & Max $(\mathrm{cm})$ & 19 & 28 & 14 & 13 & 7 \\
& Ave $(\mathrm{cm})$ & 11 & 11 & 8 & 7 & 4 \\
\hline
\end{tabular}

Table 2 Germination percentage and root length of the Bahia grass in field test.

\begin{tabular}{lcccccc}
\hline \multicolumn{2}{l}{ Conc. Of PAM } & $10000 \mathrm{ppm}$ & $1000 \mathrm{ppm}$ & $100 \mathrm{ppm}$ & $10 \mathrm{ppm}$ & $0 \mathrm{ppm}$ \\
\hline \multicolumn{2}{l}{ Germniation percentage } & $43 \%$ & $44 \%$ & $44 \%$ & $43 \%$ & $41 \%$ \\
\multirow{2}{*}{ Root length } & Max (cm) & 20 & 18 & 25 & 18 & 8 \\
& Ave (cm) & 12 & 12 & 13 & 12 & 7 \\
\hline
\end{tabular}




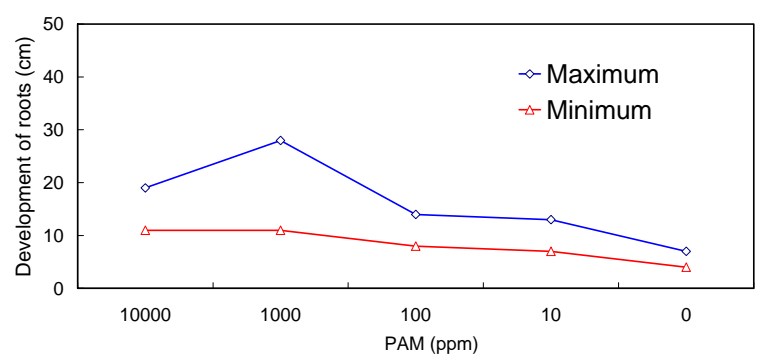

Fig. 5. Effect of PAM on the development of roots of bermuda grass

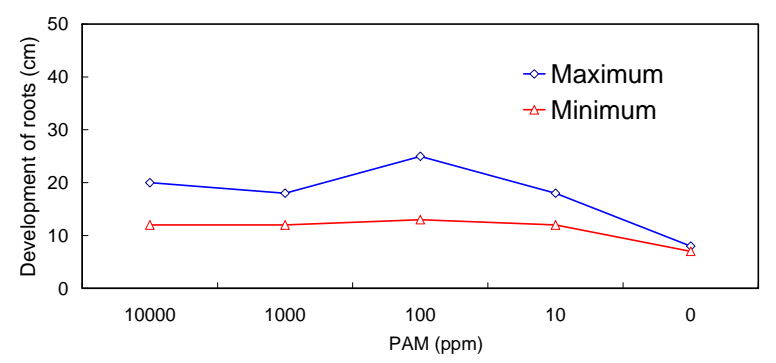

Fig. 6. Effect of PAM on the development of roots of bahia grass

\section{Conclusions}

Experimental results showed that:

1. PAM could enhance the stability of the soil aggregates and reduced the soil loss. It reduced the soil erosion for the silty clay loam by aggregating the small soil particles. The enhancement was most prominent for small particles.

2. The addition of PAM would delay the germinations of seeds of the Bermuda and Bahia, however it did not affect their survival rates.

3. PAM could enhance the growth the Bermuda and Bahia grasses.

\section{References}

[1] G. J. Levy and W.P. Miller, Polyacrylamide adsorption and aggregate stability, Soil Tillage Res., Vol. 51 (1999), p. 121-128.

[2] J. H. Lu., L. Wu., and J. Letey, Effects of soil and water properties on anion polyacrylamide sorption, Soil Sci. Soc. Amer. J., Vol. 66 (2002), p. 578-584.

[3] F. W. Barvenik, Polyacrylamide characteristics related to soil applications, Soil Sci., Vol. 158

[4] W. P. Miller, R. L. Willis and G. J. Levy, Aggregate stabilization in kaolinitic soils by low rates of anionic polyacrylamide, Soil Use Manage., Vol. 14 (1998), p. 101-105. 